\title{
Innovative Tools for the Effectiveness and Efficiency of Administrative Action of the Metropolitan Cities: the Strategic Operational Programme
}

\author{
Francesco Calabrò ${ }^{1, a}$, Lucia Della Spina ${ }^{1, b}$ \\ ${ }^{1}$ Mediterranea University of Reggio Calabria. PAU - Department of Heritage, Architecture, Urban \\ Planning, Via Salita Melissari - 89124, Reggio di Calabria, Italy

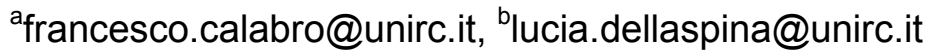

\begin{abstract}
Keywords: Strategic Plan, Strategic Operational Programme, Evaluations.
\end{abstract}
\begin{abstract}
The urban policies and territorial live a period of profound transformation, characterized by a shift to new approaches and governance tools. At the end of a period characterized by the need to overcome the rigidity of the urban plan, which resulted at the operational level extreme fragmentation of instruments and types of intervention, today we are witnessing a phase of overall rethinking of the strategy and operational tools.

Decisive for the purposes of this change are no results the impulse of European urban policy, the uncertainties of the national framework and the new requirements for the financing of interventions related to the lack of public resources. Despite this, there is the general feeling, that current approach to urban policies, is not the proper one to face the new challenges that the city, in a context of increasing global competitiveness, are called to face.

The present work draws inspiration from arrangement of urban and territorial policies hypothesized in the last decade, with particular reference to the role of promotion that the newly founded metropolitan cities could have for economic growth and development of the territories, in order to propose an innovative model of operational planning strategic that seeks to integrate two essential aspect: the strategic component and the programmatic component, in order to lend greater administrative action of the government of the metropolitan cities.
\end{abstract}

\section{Introduction}

Since Eighties there is talked of Metropolitan City and always discussed on meaning of this concept and the implications which derive. Everyone agrees to see the institution of Metropolitan City like an opportunity to rationalize and link many aspects of our territory, from economic to the provider of services to the citizens and businesses [1].

Unlike the consolidate experiences of other countries, the notions of "metropolitan area" and "metropolitan city" (the latter already provided in the article 114 of Italian Constitution as one of local territorial Enties) have been transposed in Italy for the first time on legislative feature with the reform on local autonomies of 1990. The VI chapter (artt. 17-21) of the act 8th June 1990, n.142, outlines in fact a new model of metropolitan govern at supra-municipal scale, according to an institutional organization increasingly decentralized, under the subsidiarity principle.

The need to provide the big metropolitan areas of supra-municipal institutions born historically from several exigences. From one side, the centrality of metropolitan areas is appeared clear in the internationalization and globalization processes, at least in Europe with the announce of the project Grande Mercato Europeo in 1985, which was followed a prolonged period of intense investments from great multinational companies - industrial, financial and commercial- in the "gateways" of big metropolitan cities. The process ended in 1992, the year of project's approval of Mercato Unico [2, 3], but it was presented again later with more selective characteristics: some cities continued own growth and attractivity, while others - among these great italian cities (Milano and even more Rome) - remained essentially unchanged in the urban european hierarchy and there were surmounted by european cities also smaller size and minor history [4]. On the other part there are intense economic and political processes that lead the great cities to invest on the new large network 
of transport and communication. See for example the decisions about the creation of large network of high-velocity transport, which linked the great capitals of North Europe in the ' 80 and '90 [5].

Then today the urgent challenges for our country - and also for the other european countries amplified beyond by a strong crisis, are essentially two : the economic, territorial and planning challenges. These are increasingly braided, because an efficient and qualitative territory is an attractive and competitive element and because only a development that can involve the whole productive capital, cognitive and innovative being in the large area can be able to relaunch our great cities.

The recent Draft Law Delrio, ddl n.1212/2013, approved at the Senate the 26th March 2014, nowadays in discussion at the Chamber of Deputies, in the part dealing Metropolitan City discounts an insufficient reflection from the territorial culture and an insufficient political discussion about theme. It's be necessary in fact, as the initial draft law confirms, "a flexible instrument of govern, with large and strong competences, able to be the engine of development and involving the most productive areas in the great city network of world":so it's an institution very strong, which delegate from municipal and regional level functions of programming and planning of large area, able to explain the new needs of economy and society relaunching new and wide projectualities.

The legislative proposal goes in a different direction, Metropolitan Cities are similar greatly to the new provinces, in that all fundamental functions are those assigned to the provinces: town and country planning of pure coordination, inner infrastructures and mobility services, environment, scholastic network.

The legislative provisions define the metropolitan cities like local authorities of wide area, with the institutional aim to care the strategic development of the metropolitan area (Draft Law $\mathrm{n}^{\circ} 1212 / 2013$ "Measures on Metropolitan Cities, the Provinces, the unions and fusions of municipalities").

Among the key functions assigned to the Metropolitan City (art. 8 Draft Law n ${ }^{\circ} 1211 / 2013$ ), are also included the:

a) adoption and the annual update of the Strategic Plan of the metropolitan area, as an act of address for the institution and exercise of the functions of municipalities and associations of municipalities included in the area;

b) general land use planning;

c) structured management of public services;

d) mobility and viability, including by ensuring the compatibility and consistency of municipal urban planning within the metropolitan limit;

e) promotion and coordination of economic and social development, including by ensuring the support for economic activities and innovative and coherent research with the vocation of the Metropolitan City as outlined in the Strategic Plan of the territory referred to in subparagraph a);

f) promotion and coordination of computerization and digitization system.

From a careful examination of the functions attributed to the metropolitan cities emerges that there is still a split between the moment of the strategic choices of development, the spatial organization of the territory in which strategic decisions should be annexed, and the allocation of economic resources necessary to implementation of the same decisions.

In the draft law we still find:

- the Strategic Plan (SP) : a tool of coordination and orientation, that is possible (and very useful) starting also in absence of institutional revolutions, as demonstred by several generations of SP that have been succeeded in Italy since Nineties;

- the promotion of development, leaved totally without resources;

-The general country planning, not better defined in art.1 of law that duplicates and risks to flatten out on provincial coordination planning. 


\section{Approaches and limits of the Strategic Planning}

The intense economic and social transformations in act in our society are making ever more difficult the fundamental task of territories'govern that subordinates to public administrations.

The public administrations, in order to answer at this exigences and to face the several soliciations caming from society, but another time especially the territorial agencies, are adapting gradually to perform a new role.

In order to face the new challenges imposed by the rapid evolutions of technology and by the growing dynamics of globalized market in all developed Countries are diffusing new and articulated strategies of integrated and negotiated planning between public and private actors, of development's strategy and processes of innovation.

There are new models of programming and projectation of public functions and intervents; these are models built around the processes more opened and efficient of coordination between all institutional subjects (of association of category and trade union and all variegate local world for profit and no-profit). Their principal scope is identifying the principal choices on which focusing to guarantee the economic growt and social sustainability in the medium-long period.

In the last years, in this sense, the processes of integrated planning received an increasing attention from some italian cities, on the base of foreign examples of succeess, as suitable method to develop new forms of urban and territorial governance [6].

Identifying, through the Strategic Plan, a shared vision of development, in a dimension of wide area and of medium-long period, the integration of politics and dialogue between interlocutors of territory, have given a perception to overcome the limits (efficacy, efficiency, legitimation) of traditional planning (not only at urban scale) and to build a governance model able to make the govern's capacity of city more strong and their repositioning in Italy and Europe [7].

Here we assume "the crisis of some traditional planning models" (Regulatory Plans and derivatives) but even the experiences of advanced planning (think of the structural plans, for example) have encountered many difficulties to achieving the goals for which they were born. It has long been been recognized the inability of traditional planning instruments (Regulatory Plans and derivatives) to effectively govern the urban and territorial transformations; on the other hand, however, these processes are supported by the tools of economic planning, even at the regional level. Also the quality of urban planning instruments from nature normative-regulative is totally unsatisfactory.

It is by considerations like this that from the 1990s onwards has opened the season in Italy of the Complex Programs (introduced by Law 179/92), of the tools negotiated planning and of the Strategic Plans, all tools considered able to respond to limits of the ordinary tools of planning until then used $[8,9,10]$.

In particular, the Strategic Plan has been by many considered the necessary completion of the allocation of planning of cities, able to overcome criticality of the past in virtue of its constitutive process $[11,12]$. It is in this direction that have chosen to move, at different times, the metropolitan areas, such as for example, Bologna, Florence, Rome.

In fact, the Strategic Plan, borns from participatory processes through which is built consensus around the strategic choices of the territory; for these reasons it is able to deal with issues that can hardly find hospitality in traditional urban planning tools, as for example the:

- dynamic intersectoral;

- integrated approach;

- services of a social nature and environment and, more generally, the organizational aspects;

- selection of priorities for action.

It is also true that, there are also the limits one's own of the Strategic Plan that are its poor operation, imputable to: 
- lack of the pre-feasibility and sustainability evalutation of the actions;

- lack of evaluation of the economic resources for the implementation of actions;

- definition of the relative timing of implementation.

De facto we are witnessing a kind of abdication of technical and professional expertise in the name of a supposed democratic choices: paradoxically, it is easier than find hospitality in a Strategic Plan popular choices but damaging to the community, rather than unpopular choices but useful.

In contrast, ordinary tools of economic planning, such as the Regional Operational Programmes, are characterized by the presence of these factors: is defined the period of time, even in the intermediate steps, and they are equipped of the necessary funding.

But, they at the same time, not conside of spatial projection of the investments planned, because allocate the financial resources to the implementation of a strategy distinct from that of the Strategic Plan that of planning instruments.

\section{Innovative tools for the effectiveness and the efficiency of the administrative action of the Metropolitan Cities: Strategic Operational Programme}

It is spreading, by now, the awareness of the limits of the dichotomy between the choices territorial planning and strategic and the decisions regarding the allocation of resources [13]. The Region of Emilia Romagna, for example, is oriented towards the Territorial Planning interpreted here as a moment of integration between traditional subdivisions in economic planning and territorial planning, to offer spatial references to development policies.

Is therefore necessary to equip itself of innovative tools, able to switch quickly and effectively from the conception stage to the the implementation phase, able to control some key issues: the time and resources needed to achieve the objectives, the subjects to be involved in the implementation phase, the feasibility and three-dimensional sustainability of the interventions necessary.

Must be tools capable of learning from reality and self-correcting on-goin, passed the limits of strategic plans as they are conceived today, introducing inside of strategic plans the programmatic operative component.

The most appropriate tool, therefore, to give real incisiveness administrative action of the new entity created by the Metropolitan Cities, it should be a tool capable to bring a synthesis the specificity of the other tools: we could define it the "Strategic Operational Programme".

Concomitant use of terms such as "operative" "strategic" to designate something it might display a contradiction.

The POS "Strategic Operational Programme" should be intended here as a synonym for "Operative Program of Strategic Actions": in this sense, it should be the last phase of the Strategic Plan.

The passage from the Strategic Plan to Strategic Operative Program is filtered from the evaluations: feasibility, sustainability (a three dimensions), effectiveness and efficiency of operations.

Therefore, according to the classical model of operational programs, after an evaluation phase, at the strategic actions selected are allocated resources, time, subject and method of implementation; in this way are exceeded the weaknesses of a tool such as the Strategic Plan, which, however, constitutes an improvement compared the classical approach to urban planning.

This is the tool that they need Metropolitan Cities for to be an entity that contributes really to the competitiveness of the territory in a manner different from the past. 


\section{Assessments as moment accompanying and synthesis of innovative pathways and instruments for the government of the territory.}

Public intervention implemented through programs active an application for assessment: beyond the explicit applications contained in the various intervention tools, the decision-making sphere, facing the loss of representativeness of organized politics and the growing complexity of the variables that influence the public choices has the absolute necessity of auxiliary tools that allow you to optimize the use of available resources and at the same time make the decision-making path shareable and transparent .

Evaluations therefore, can make a key contribution to the proper functioning of democratic systems, within a scenario marked by increasing levels of conflict between the social partners and between the geographical areas.

The tools for the programmed intervention on the territory put the public decision-maker faced with the need to choose between alternative programs and projects, in a general condition of scarce resources. The problem of choice, far from being merely technical, invests in full the founding principles of the contemporary democratic society.

The classic problem of public decision-makers, until recently it was the decision to allocate the public resources among possible alternative uses. It was, therefore, to understand how it was maximized total utility, or, in other words, to what extent any possible alternative use contributed in the growth of collective utility.

This, of course, greatly simplifying the terms of the problem, which actually had greater degrees of complexity. Just to name a few, just reflect on the fact that there is no one collective usefulness but the benefits are diversified for social groups, for territorial portions etc. and that have a impact differently on each of the recipients.

The transformations occurred in recent years, in particular the different approach to economic policies, they have also changed the terms of the problem.

The most advanced systems are oriented towards state intervention to private initiative that provides, to private initiative, the informations on future scenarios that will allow it to optimize their choices.

The transfer to private entities of functions previously acquitted by public bodies and the role of promoting the development of the various programming tools, adds an extra degree of complexity, while not radically altering the conceptual framework.

It is no longer only consider proposals for public but becomes necessary to evaluate the extent to which private initiatives contribute to achieving the objectives set by the policy maker.

A further change occurred in the objectives to be pursued: the awareness of the limits of development understood only in terms of economic growth, has changed the very aims of public intervention (considering in this sense also the private sector with public purposes).

The environmental sustainability of interventions, for example, is in addition to the traditional objectives such as increased production or social equity.

\section{First elements for the construction of the evaluation model}

The passage from the Strategic Plan to the Strategic Operational Programme is filtered from the evaluations: according to the classical model of the Operational Programmes, after an evaluation phase, to the strategic actions selected, are allocated resources, time, subject and method of implementation; thus are exceeded the weaknesses of a tool such as the Strategic Plan, which, however, has been an improvement over the classical approach to urban planning.

The culture of evaluation, therefore, is the element that pervades the entire program, systematizing and making to dialogue all the necessary specialist contributions in the different phases, from the point of conception to its realization [14].

In a such program the evaluations to fulfill at least two different purposes:

- Improving the effectiveness and efficiency of public action; 
- Create the necessary social consensus around such action.

In order for these goals to be pursued, is necessary that the evaluation process meets two fundamental principles:

- The transparency of the decision-making process;

- The scientificity of the process, understood as its falsifiability.

The evaluation activity takes, even in this case, the now customary appearance of three-step process, ex ante, ongoing and ex post. In methodological terms it can be said that in the three phases should be prepared four types of assessment [15]:

- Coherence

- Sustainability

- Effectiveness

- Efficiency

for each of which must be identified the technique instrumentation to use, depending on the specific query of evaluation, and selected the most appropriate set of indicators (outcome, impact and implementation).

The Evaluation of Coherence should be carried out in the ex ante phase and can be either internal or external. To ensure consistency of the program means that the environmental actions / projects planned are comply with the objectives and strategy, while the external coherence is assessed in relation to the plans / programs with which interacts the program in construction.

The assessment of effectiveness is a type of evaluation that belongs to all three phases of the program: ex ante predictions are made about the expected results of actions / projects selected, ongoing will be measured partial results and ex-post the final ones.

The evaluation of sustainability means to move in the frame of sustainable development and therefore means not only to develop programs consistent and efficient but also able to produce economic, environmental and social effects such as to improve the living conditions of the citizens without prejudice to the opportunities for future generations. Synonym for Sustainability, in this context, can be considered the concept of feasibility. The actions under the Strategic Operational Programme will be feasible even to the extent that will be sustainable: the assessments, therefore, will aim to verify the actions in this respect too.

The assessment of efficiency is essentially a measure of the degree and of the mode of implementation of the program, and as such obviously has a character forecasting ex ante, while ex post it accompanies the required monitoring activities.

During the ex-ante evaluation will be built first and foremost an intervention strategy through the prioritization of the objectives identified in a concerted manner by the institutions and the social partners involved. Then will select the actions / projects on the basis of their ability to contribute to the objectives, as measured by the three-dimensional assessment of their sustainability, by preidentifying indicators to measure it. More in general, then, will be quantified the expected results relative to the entire program.

In the subsequent phases must be checked the distance between the forecasts and the degree of programmatic implementation gradually achieved, identifying the causes of delays, the change of the system of needs and then providing the information to adjust accordingly the program.

\section{Conclusion}

Given the growing complexity of the territorial government, the method of strategic planning has established both itself as a reference model that as one of the most important elements of innovation in urban and territorial governance emerged in the last twenty years.

However, as affirm by the OECD [16], in most of the large urban areas of developed countries, the governance structures not appear today suitable to the new tasks, that are those to ensure the economic prosperity, the social cohesion, environmental sustainability and citizen participation. 
It is also possible to state that the deep economic and social transformations taking place in our society are making more and more complex the fundamental task of government of the territories which belongs to the public administrations. And so the transformation of the territory constituting the complex decision problems and, therefore, emphasize the need, today more and more urgent to have an appropriate evaluation tools, but also the need for greater integration of the evaluation in the stages of design and planning.

In this perspective, evaluation and design appear concepts inseparable and the evaluation becomes an element of decision support territorial transformation, more effective the more integrated into the process territorial government.

In this respect, the Strategic Planning, despite having introduced "innovations" (process and product) in the urban context, in the actors and in their relationships, has shown limited effectiveness and practicality in the evaluation phase of the alternative scenarios of urban transformation; this latter represent a class of decision problems that for can be solved, need to be placed in a correct "evaluation framework", this guaranteeing the analysis and evaluation of the effects of the choices that for the city can prove to be "strategic" and capable to provide development opportunities for territory and greater competitiveness for the same on a large scale.

These limits, in our opinion, can be overcome through the POS "Strategic Operational Program" that brings together the strategic component with the component of economic planning, and in which the the evaluation becomes an integral element that pervades the entire strategic planning process.

\section{Acknowledgments}

The paper is the result of the joint work of the two authors. Despite the overall responsibility being equally shared, Lucia Della Spina is responsible for "Approaches and limits of the Strategic Planning" paragraph, and Francesco Calabrò is responsible for "Assessments as moment accompanying and synthesis of innovative pathways and instruments for the government of the territory" paragraph. The paragraphs: "Innovative tools for the effectiveness and the efficiency of the administrative action of the Metropolitan Cities: Strategic Operational Programme" is the result of the joint work of the two authors: Francesco Calabrò and Lucia Della Spina.

\section{References}

[1] R. Camagni: Le aree metropolitane italiane per lo sviluppo del paese: obiettivi e competenze nella nuova legge, relazione presentata al Convegno "Le città metropolitane: una riforma per il rilancio del paese", Firenze, 6 febbraio 2014

[2] R. Camagni: Le grandi città italiane e la competizione a scala europea. In: P. Costa e M. Tonilo (eds), Città metropolitane e sviluppo regionale, Franco Angeli, Milano, (1992), pp. 2345

[3] R. Camagni, M.C. Gibelli: Cities in Europe: globalization, sustainability and cohesion. In: Presidenza del Consiglio dei Ministri, European Spatial Planning; Rapporto presentato alla Riunione dei Ministri delle Politiche Territoriali, Venezia, 3-4 maggio. Poligrafico dello Stato, Roma, (1996), pp. 91-175

[4] R. Camagni: Presentazione. In: Osservatorio sulla Qualità della vita a Milano, Milano (2013)

[5] R. Camagni: Economic role and spatial contradictions of global city-regions: the functional, cognitive and evolutionary context. In: A. Scott (ed.): Global city-regions: trends, theory, policies, Oxford University Press, Oxford, (2001), pp. 96-118

[6] A. Tanese, E. Di Filippo, R. Rennie (ed.): La pianificazione strategica per lo sviluppo dei territori, Rubettino (2006) 
[7] R. Florio (ed): Pianificazione strategica. Istruzioni per l'uso. 10 anni di Pianificazione strategica in Italia, Ragioni, esiti, criticità, Firenze (2010)

[8] M. De Pascale: Gli strumenti per la programmazione dello sviluppo locale. In: P. Baldi, A. Bruzzo, A. Petretto (eds), Programmazione regionale e sviluppo locale: recenti esperienze in Italia. Edifir. Firenze (2008)

[9] F. Calabrò, L. Della Spina: The cultural and environmental resources for sustainable development of rural areas in economically disadvantaged contexts. Economic-appraisals issues of a model of management for the valorisation of public assets. In: 3rd International Conference on Energy, Environment and Sustainable Development (ICEESD 2013). Advanced Materials Research Vols. 869-870 (2014) pp 43-48 (C) (2014) Trans Tech Publications, Switzerland doi:10.4028/www.scientific.net/AMR.869-870.43, (2014)

[10] F. Calabrò, L. Della Spina: The public-private partnerships in buildings regeneration: a model appraisal of the benefits and for land value capture. In: 5nd KKU International Engineering Conference 2014 (KKU-IENC 2014). ADVANCED MATERIALS RESEARCH, Vols. 931932 (2014) pp 555-559 (C) (2014) Trans Tech Publications, Switzerland doi:10.4028/www.scientific.net/AMR.931-932.555, (2014)

[11] D. Cavenago: Città e piano strategico, Il Sole 24 Ore. Milano (2004)

[12] P. Healey, A. Khakee, A. Motte, B. Needham (eds): Making Strategic Spatial Plans. Innovation in Europe. UCL Press. London (1997)

[13] F. Vescovi: Progetto urbano strategico e competitività delle aree metropolitane. Libreria Clup, Milano (2006)

[14] M. Palumbo: Il processo valutativo, Milano, FrancoAngeli (2002)

[15] S. Moroni, D. Patassini (eds): Problemi valutativi nel governo del territorio e dell'ambiente, Milano, Franco Angeli (2006)

[16] OCSE, The reform of metropolitan governance, (2000) 